\title{
Experimental Study on the Comprehensive Identification and Improvement of Dispersive Soil in Western Jilin Province, China
}

\author{
Jun Yang, Yi Song, Rui Fu $\mathbb{D}$, Changwei Lu, and Hongcheng Liu \\ Jilin Province Water Resource and Hydropower Consultative Company of P R China, Changchun, Jilin 130026, China
}

Correspondence should be addressed to Rui Fu; ruifu13@163.com

Received 21 June 2021; Revised 15 August 2021; Accepted 18 August 2021; Published 15 September 2021

Academic Editor: Xudong Zhang

Copyright (c) 2021 Jun Yang et al. This is an open access article distributed under the Creative Commons Attribution License, which permits unrestricted use, distribution, and reproduction in any medium, provided the original work is properly cited.

\begin{abstract}
In this study, physical experiments, clay mineral determination, and $\mathrm{pH}$ testing were performed to examine the basic properties of soil samples from a soil material yard selected for dam construction at Hua'ao Lake, Qian'an County, Jilin Province, China. The results show that the soil in the study area is cohesive, the mineral content of illite in the illite/montmorillonite mixed layer is approximately 50\%, and the $\mathrm{pH}$ value of the environment from which the soil samples were taken is 8.43-8.91. These factors enable the soil in this area to be dispersed. The dispersibility of the soil sampled from this area was evaluated by a double hydrometer test, a pinhole test, a fragmentation test, a sodium adsorption ratio test, and determination of the percentage of exchangeable sodium ions. Because these test methods had inconsistent results, the test methods in combination with the typical geomorphic conditions of the sampling points were ultimately used to comprehensively evaluate the soil dispersion. The results demonstrate that the cohesive soil sampled from the soil material yard is dispersible and must be treated with improvement measures before it can be used as a filling material for the dam. To improve the dispersive and transitional soil, 2\%, 3\%, 4\%, 5\%, and 6\% $\mathrm{L}_{1} \mathrm{Fa}_{2}$ (a $1: 2$ ratio of lime and fly ash) and $\mathrm{C}_{1} \mathrm{~L}_{1} \mathrm{Fa}_{4}$ (a $1: 1: 4$ ratio of cement, lime, and fly ash) were used to perform improvement tests on 10 groups of dispersive soil samples and 10 groups of transitional soil samples. The results reveal that the addition of $4 \%$ $\mathrm{L}_{1} \mathrm{Fa}_{2}$ best improves the dispersive soil in this area. Therefore, the soil intended for this project should be used as a dambuilding material after improvement with the $4 \%$ addition of $\mathrm{L}_{1} \mathrm{Fa}_{2}$.
\end{abstract}

\section{Introduction}

In the 1930s, American agricultural soil scientists first discovered the existence of soil with self-dispersing properties, and dispersive soil has since been gradually discovered worldwide [1]. Dispersive soil has a high content of sodium ions, and the soil particles are easily dispersed into primary particles in water or pure water with a low salt content; thus, dispersive soil is easily eroded. Consequently, serious engineering accidents can easily occur if the nature of the dispersive soil is unclear or if the dispersibility of the soil in the engineering area is not ascertained before the construction of a project. For example, channels in dispersive soil distribution areas are prone to erosion, which may form gullies and even landslides. The use of dispersive soil as a dam material also likely causes seepage and piping damage, which can cause heavy casualties and economic losses [2-7]. To reduce the lack of understanding of dispersive soil, some scholars have studied how to identify dispersive soil and investigated improvement measures. The improvement of dispersive soil plays an important role in engineering construction, and engineering practice in areas with dispersive soil also urgently requires research on related prevention and control measures [8]. Therefore, it is particularly important to study the identification and improvement of dispersive soil.

Some researchers have explained dispersibility by studying the ion content in the soil and the $\mathrm{pH}$ of the soil environment. Other scholars have both qualitatively and quantitatively determined the dispersibility of soil via various test methods. According to the unique properties of dispersive soil, researchers have proposed test methods including the use of pinholes, fragments, double hydrometers, soluble cations in pore water, and exchangeable sodium 
ions to explain the dispersion of soil samples [9-18]. While dispersive soil is classified according to the degree of dispersion, various test methods often have inconsistent evaluation results. Therefore, some researchers have proposed comprehensive identification methods. For example, Zhang et al. [1] simulated the process of salt migration with water in dispersive soil through experimental equipment. The effect of physical and chemical properties on soil dispersion was studied by grey correlation analysis. Finally, the main factors affecting the dispersion are determined. Zhang et al. [19] quantitatively studied the relationship between the contents of $\mathrm{Mg}^{2+}$ and $\mathrm{Ca}^{2+}$ and their relative relationships in dispersive soil. The results show that when the content of $\mathrm{Ca}^{2+}$ in clay is higher than that of $\mathrm{Mg}^{2+}$, the permeability of clay is lower and the dispersibility is stronger. Zhang [20] analyzed the law of the variation of clay dispersion in the vertical depth range via pinhole experiments and other methods. Shi [12] assigned weights to the results of different test methods and assigned scores to soil dispersibility levels, based on which they ultimately comprehensively determined the dispersibility levels of soil samples. Moreover, they summarized the relationship of the distribution law, formation mechanism, geomorphology, hydrometeorology, and chemical composition of the environmental water of dispersive soil and provided suggestions for construction projects in the study area. Peng [13] analyzed the dispersibility of low-liquidlimit clay via various test methods, and the results revealed that the double hydrometer test and pinhole test were not suitable for the identification of the dispersibility of such soil samples. Zhu et al. [14] studied the dispersion flocculation kinetic characteristics of clay by changing the $\mathrm{pH}$ value in soil. The results show that the dispersion behavior of clay is closely related to cation. The dispersion of clay can be explained by $\mathrm{pH}, \mathrm{EC}$, ionicity, and average particle size of the cationic system in clay. Zhang et al. [16] considered the influence of steam flow on the thermal movement and the relationship between saturation and the porosity ratio; then, they established an improved mathematical model to provide a reference for the analysis of the destruction process of soil in harsh geological environments of cold, arid, and salted areas. Liu et al. [17] used the mercury injection porosity method to study the pore characteristics and pore distribution of concrete under the condition of dispersive water. The results show that the addition of slag powder can improve the pore size distribution of concrete under dispersive water condition, which is beneficial to improve the durability of concrete. Zhang et al. [21] took the typical frozen soil in western Jilin as their research object, and combined with field monitoring data, they studied the characteristics of thermohydrodynamic and freezing depth in the freezing process of soil. The results can be used for reference in the study of water-thermal coupling of dispersive soil in this area.

To eliminate the adverse effects of dispersive soil on engineering construction, researchers have made many attempts to improve dispersive soil, and most have added a certain proportion of additives to study the improvement effect. For example, Deng et al. [4] improved dispersive soil by adding different proportions of lime powder, and the results demonstrated that the improvement effect was the best when the content was approximately $1 \%$; when the content exceeded $3 \%$, the dispersibility was enhanced with increasing salinity tolerance. Li [22] applied the microbial mineralization technology of urease-induced calcium carbonate deposition to improve dispersive soil and identified and evaluated the dispersion of the improved soil samples; the findings revealed the innovation of the combination of green microbial mineralization technology with the improvement of water conservancy dam materials. Savaş et al. [23] carried out pinhole test, fragmentation test, and unconfined compressive strength test by adding different percentages of fly ash to dispersive soil. The improvement effect of different grades of fly ash on dispersive soil was studied. Savas [24] studied the changes in the consolidation and expansion characteristics of dispersive soil by adding lime and natural zeolite and obtained the optimal additive dosage for an improvement effect. Scheuermann Filho et al. [25] investigated the effects of two additives on the strength and durability of dispersive soil by adding pulverized glass powder and calcium carbide lime to dispersive soil. Furthermore, taking other factors into account, some researchers conducted experiments. They studied the effect of amendments on the performance of dispersive soil [26-32].

Most of the previous research on dispersive soil focused on test methods and result analyses, and the improvement of dispersive soil mostly focused on indoor studies on the effect of a single improvement measure. There has been little research on the improvement of dispersive soil in western Jilin Province, China, and no case has been applied to practical engineering. In this study, various experimental methods were used to comprehensively identify and analyze the dispersibility of samples from the soil material yard selected for dam construction in Hua'ao Lake, Qian'an County, Jilin Province, China. Two improvement measures were used to improve the dispersive soil: $\mathrm{L}_{1} \mathrm{Fa}_{2}$ (a $1: 2$ ratio of lime and fly ash) and $\mathrm{C}_{1} \mathrm{~L}_{1} \mathrm{Fa}_{4}$ (a $1: 1: 4$ ratio of cement, lime, and fly ash).

\section{Materials}

2.1. Topographic and Geomorphic Conditions of the Soil Sampling Points. A clay core dam must be constructed to shield a protected area from water in Hua'ao Lake, Qian'an County, western Jilin Province, China (Figure 1).

Considering the economic practicability and convenience of engineering construction, the required soil materials for dam construction were selected from the lake depression and microwave-shaped hilly land near the dam site. The lithology is alluvial loess-like loam, belonging to the Guxiangtun Formation of the Pleistocene Quaternary. According to a field investigation, there are microlandforms and dispersive soil phenomena in the study area, such as dissolution ditches, dissolution caves, water turbidity, clay soil deposition, and cracking after the water has dried (Figure 2). According to engineering survey data from the vicinity of this site, the soil of this yard may be characterized by dispersion. Dispersive soil easily decomposes when it is in contact with water. To ensure the safety of the clay core dam, 


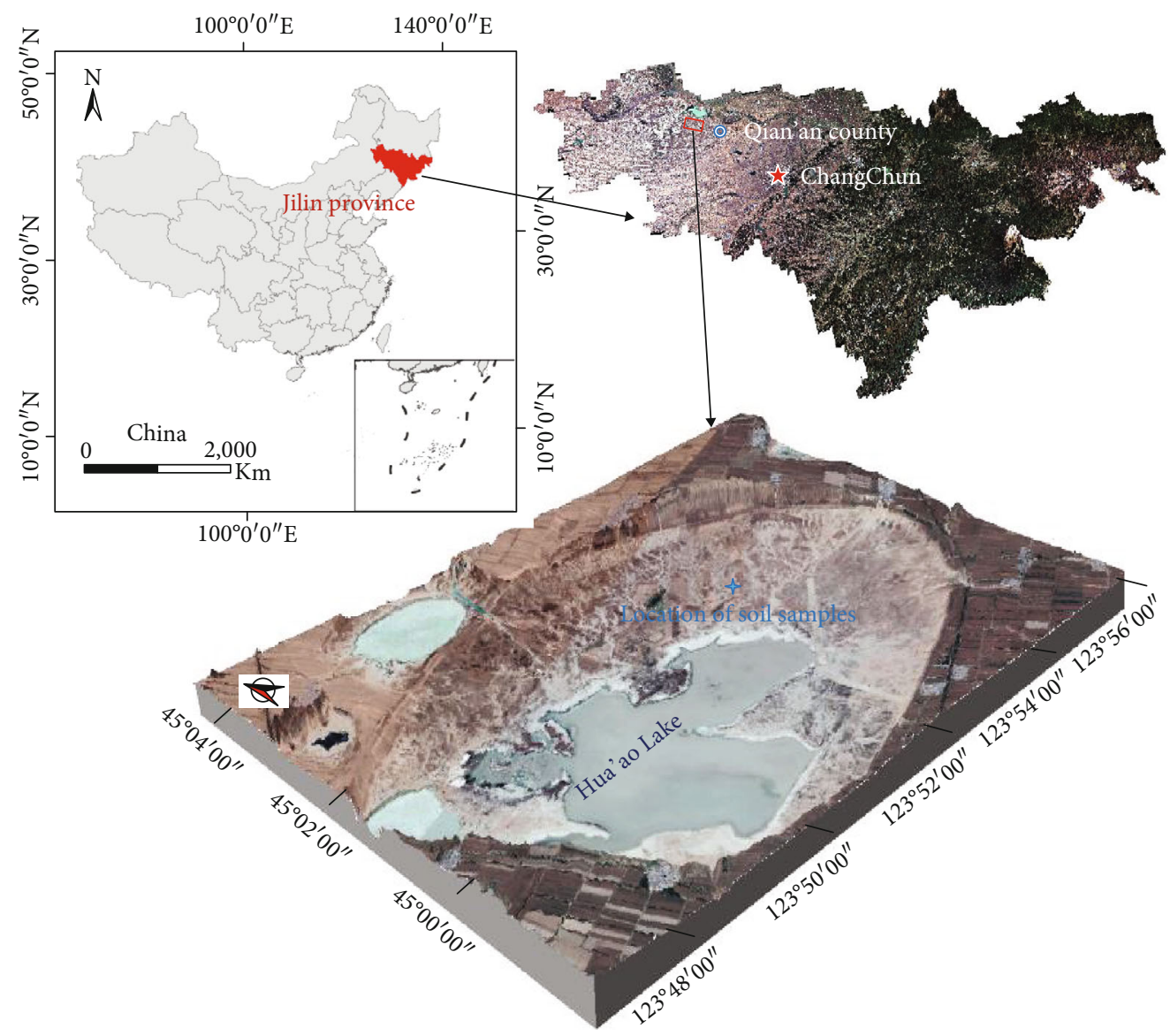

FIgURE 1: Location and topographical and geomorphic conditions of the study area.

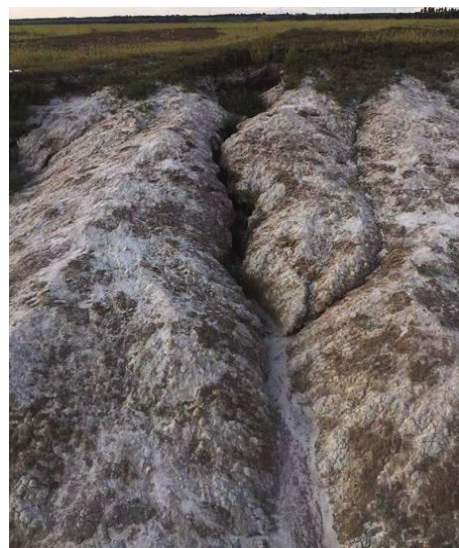

(a)

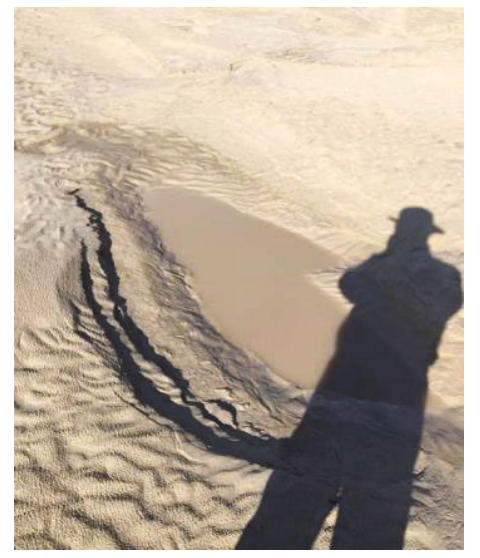

(b)



(c)

FIGURE 2: Dispersion characteristics of the soil in the study area: (a) dissolution phenomenon; (b) water turbidity; (c) cracking phenomenon.

it is necessary to study the dispersibility of the soil and potential improvement measures.

2.2. Composition of Soil-Like Material. In this study, 221 soil samples were collected from survey boreholes. The basic properties are reported in Table 1. According to the test results, the sample was cohesive, fine-grained soil, and $I_{p}=$ $19.8>17$. The moisture content was $W=23.0 \%$, which indi- cates a wet state (20-30\%), and $I_{L}=0.32$, which indicates a plastic state (0.25-0.75).

2.3. Chemical Composition of the Soil Samples. The species of clay minerals in soil are closely related to soil dispersion. When the content of montmorillonite is low, the contents of illite and kaolin are high, there are sufficiently many $\mathrm{Na}^{+}$ions between layers, and dispersive soil may be formed. To analyze the spatial distribution of atoms in the soil 
TABLE 1: Basic physical and mechanical properties of the soil samples.

\begin{tabular}{lccc}
\hline Property & Value & Property & Value \\
\hline Gs & 2.70 & $W_{L}(\%)$ & 40.8 \\
$W(\%)$ & 23.0 & $W_{P}(\%)$ & 21.0 \\
$\rho\left(\mathrm{g} / \mathrm{cm}^{3}\right)$ & 1.90 & $I_{P}(\%)$ & 19.8 \\
$e$ & 0.839 & $I_{L}$ & 0.32 \\
$\operatorname{Sr}(\%)$ & 91.7 & $K_{20}(\mathrm{~cm} / \mathrm{s})$ & $9.21 \times 10^{-6}$ \\
\hline
\end{tabular}

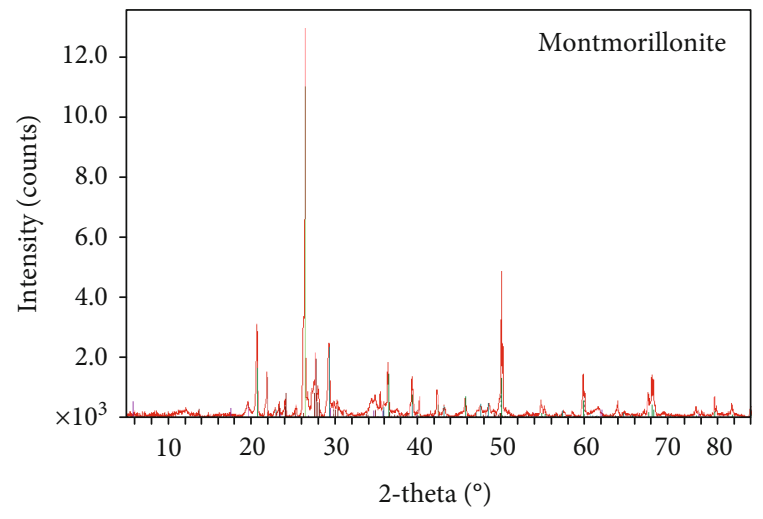

FIGURE 3: XRD patterns of the representative soil samples.

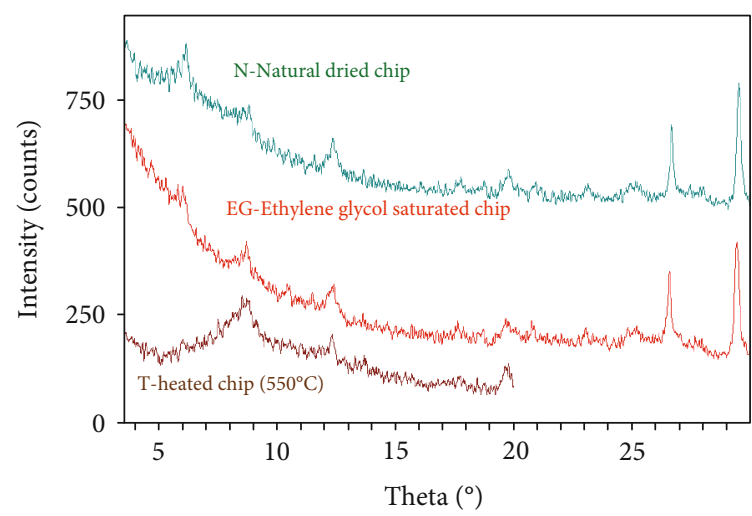

FIGURE 4: XRD analysis results of the representative soil samples.

particles, particles smaller than $2 \mu \mathrm{m}$ from the excavated samples were analyzed by X-ray diffraction (XRD). The XRD results of soil samples are shown in Figures 3 and 4. The relative contents of clay minerals are exhibited in Table 2.

Based on the preliminary analysis of the experimental results, there was a large amount of quartz in the soil particles, and the other components were heterhalite, beddite, albite, etc. The mineral content of illite in the illite/montmorillonite mixed layer accounted for approximately $50 \%$. Experience has shown that there is often a certain content of sodium montmorillonite in the mineral composition of dispersive clay; if the content in the soil is high, dispersive clay is easily formed. Therefore, based on the chemical composition analysis, the soil samples from the study area have the inherent factors of dispersibility.
2.4. $p H$ Value of the Soil Sample. To study the relationship between $\mathrm{pH}$ value and dispersibility of the soil samples, $300 \mathrm{~g}$ of air-dried soil particles was weighed by a balance after being passed through a $2 \mathrm{~mm}$ sieve, and $900 \mathrm{~mL}$ of distilled water was added at a ratio of $1: 3$ to make a suspension. A Hash $\mathrm{pH}$ meter was used to measure the $\mathrm{pH}$ values of 54 groups of representative soil samples, and the statistical results are presented in Figure 5.

As Figure 5 shows, within the sampling depth range $(\leq 2.5 \mathrm{~m})$, with increasing depth, the $\mathrm{pH}$ value first increased and subsequently decreased, and the $\mathrm{pH}$ value near the depth of $2 \mathrm{~m}$ was the highest. The $\mathrm{pH}$ value of the soil sample environment was 8.43-8.91, which indicates an alkaline environment and environmental conditions for dispersive soil.

In summary, the mineral composition and alkaline environment of the soil indicate the internal conditions of soil dispersibility, and the soil from the site was found to have dispersive characteristics. Therefore, it can be preliminarily determined that the soil is dispersive. To further identify the dispersibility of the soil samples and the degree of dispersibility, various tests were performed for comprehensive identification. Moreover, to study the properties of dispersive soil after taking improvement measures, two additives were added to the soil, and the improvement effects were investigated.

\section{Experimental Methods}

Previous research results have demonstrated that dispersive clay more easily decomposes than normal clay due to the thick water film on the surface of the clay particles, which increases the distance between crystal latches and decreases the mutual suction and shock resistance. When there are higher contents of hydrophilic minerals such as montmorillonite and illite and more $\mathrm{Na}^{+}$ions in the pore water, the water film will be thicker, and the clay will be more dispersible. Therefore, to identify dispersive clay, the mineral composition of the soil and the salt composition in the pore water were first analyzed. In addition, a pinhole test and a double hydrometer test were performed to simulate actual scour and dispersion conditions. Other relevant test methods were the fragmentation test, exchangeable sodium percentage (ESP) test, and sodium adsorption ratio (SAR) test. In this study, the dispersibility of the studied soil was comprehensively identified by these methods, and two improvement measures were used for the improvement tests: $\mathrm{L}_{1} \mathrm{Fa}_{2}$ (at a 1:2 ratio of lime and fly ash) and $\mathrm{C}_{1} \mathrm{~L}_{1} \mathrm{Fa}_{4}$ (at a $1: 1: 4$ ratio of cement, lime, and fly ash).

3.1. Double Hydrometer Method. In the double hydrometer test method, two conditions are investigated: a dispersant is added, and no dispersant is added (Figure 6). Then, the clay contents of the soil $(<0.005 \mathrm{~mm})$ under these two conditions are measured by a hydrometer, and the ratio of the clay contents measured by the two methods is the value of dispersion [9]. The evaluation standard is as follows:

$$
V_{p}=\frac{C_{\mathrm{wd}}}{C_{d}} * 100 \%
$$


TABLE 2: Relative contents of clay minerals in the representative soil samples.

\begin{tabular}{lcccccccc}
\hline & & \multicolumn{2}{c}{ Relative contents of clay minerals (\%) } & & \multicolumn{2}{c}{ Ratio between layers (I/S\%) } \\
$\begin{array}{l}\text { Soil } \\
\text { samples }\end{array}$ & $\begin{array}{c}\text { Montmorillonite } \\
\text { S }\end{array}$ & $\begin{array}{c}\text { Illite/ } \\
\text { montmorillonite } \\
\text { I/S }\end{array}$ & $\begin{array}{c}\text { Illite } \\
\text { It }\end{array}$ & $\begin{array}{c}\text { Kaolinite } \\
\text { K }\end{array}$ & $\begin{array}{c}\text { Chlorite } \\
\text { C }\end{array}$ & $\begin{array}{c}\text { Chlorite/ } \\
\text { montmorillonite C/S }\end{array}$ & $\begin{array}{c}\text { Illite/ } \\
\text { montmorillonite }\end{array}$ & $\begin{array}{c}\text { Chlorite/ } \\
\text { montmorillonite }\end{array}$ \\
\hline $\begin{array}{l}\text { Sample } \\
1\end{array}$ & - & 34 & 31 & 20 & 15 & - & 45 & - \\
$\begin{array}{l}\text { Sample } \\
2\end{array}$ & - & 37 & 27 & 28 & 9 & - & 10 & - \\
\hline
\end{tabular}

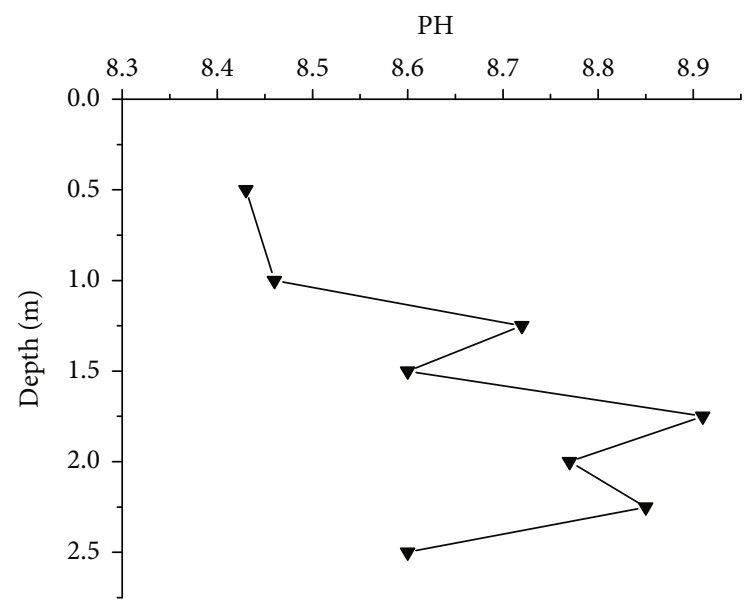

FIGURE 5: Relationship between $\mathrm{pH}$ and depth.

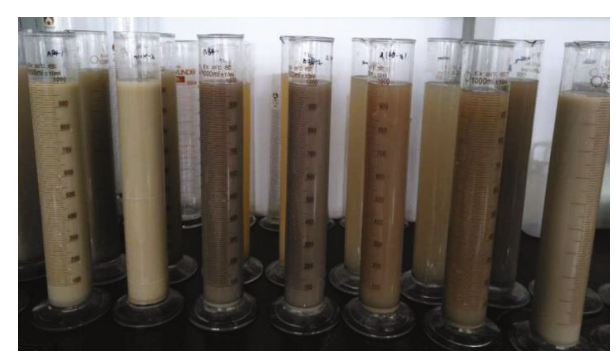

FIgURE 6: Preparation of the soil-water suspension.

where $V_{p}$ is the value of dispersion, $C_{\mathrm{wd}}$ is the amount of clay without a dispersant, and $C_{d}$ is the amount of clay with the addition of a dispersant. For nondispersive soil, $V_{p}<$ $30 \%$; for transitional soil, $30 \%<V_{p}<50 \%$; for dispersive soil, $V_{p}>50 \%$.

3.2. Pinhole Test. Soil samples were prepared in a small horizontal pipe spout meter with a diameter of $3.3 \mathrm{~cm}$ in the room. After the samples were prepared, they were cured in a moisture tank for 1 week. To simulate the scouring process of water flow on the soil pores, the soil sample was axially penetrated in a fine hole with a diameter of $1.0 \mathrm{~mm}$. The water head penetration tests were performed with distilled water along the horizontal direction of the pinhole under the action of water pressure at all levels (Figure 7). According to the experimental phenomena, test water pressure, and established judgment criteria [11], soil dispersibility can be divided into six types: highly dispersive (D1), disper- sive (D2), transitional (ND4), transitional (ND3), nondispersive (ND2), and nondispersive (ND1).

3.3. Fragmentation Test. The preparation of the samples for the fragmentation test was identical to that for the pinhole test. A cubic soil sample with a volume of $1 \mathrm{~cm}^{3}$ was immersed in a beaker containing $250 \mathrm{~mL}$ of distilled water (Figure 8). The transformation of clay particles into a colloidal suspension in distilled water was observed after soaking for 5-10 min [10]. The evaluation standards are as follows:

Class I: no reaction; the soil may collapse at the bottom of the cup, but the water does not become cloudy.

Class II: slight reaction; the water near the soil block is somewhat turbid (if it is relatively turbid, it should be listed as Class III).

Class III: medium reaction; the turbidity point of the colloid in the suspension is easily identified, and the colloid usually diffuses into pinstripes at the bottom of the cup.

Class IV: strong reaction; there is a layer of colloidal deposition at the bottom of the cup, and a portion or all of the water in the cup is turbidized.

3.4. Sodium Adsorption Ratio (SAR). The SAR is the ratio of the $\mathrm{Na}^{+}$content to the $\mathrm{Ca}^{2+}$ and $\mathrm{Mg}^{2+}$ content in the pore water solution [18]. It is a quantitative indicator to identify dispersibility by measuring the content of cations in soil. The specific test method is to first measure the liquid limit water content of the soil and subsequently stir the soil sample with distilled water into a similar state to the liquid limit water content of the dish. After standing for a sufficient amount of time, a vacuum pump was used to absorb the pore water solution, and the $\mathrm{K}^{+}$and $\mathrm{Na}^{+}$contents in the solution were determined by atomic absorption spectrometry. The $\mathrm{Ca}^{2+}$ and $\mathrm{Mg}^{2+}$ contents were obtained by titration. Then, the SAR and total dissolved solid (TDS) values can be used to determine the soil dispersion (Table 3 ), which can also be determined by combining the total amount of soluble salt cations $M_{\mathrm{TDS}}$ and the molar percentage of $\mathrm{Na}^{+}$ions $\mathrm{C}_{\mathrm{PS}}$ in the pore water. The SAR is calculated by

$$
\mathrm{SAR}=\frac{\mathrm{Na}^{+}}{\sqrt{\left(\mathrm{Ca}^{2+}+\mathrm{Mg}^{2+}\right) / 2}}
$$

3.5. Percentage of Exchangeable Sodium Ions (ESP). According to some research experience in the United States and Australia, the content of exchangeable $\mathrm{Na}^{+}$and the sum of exchangeable cations in the clay mineral structure layer can be calculated. Then, the dispersibility of soil can be 


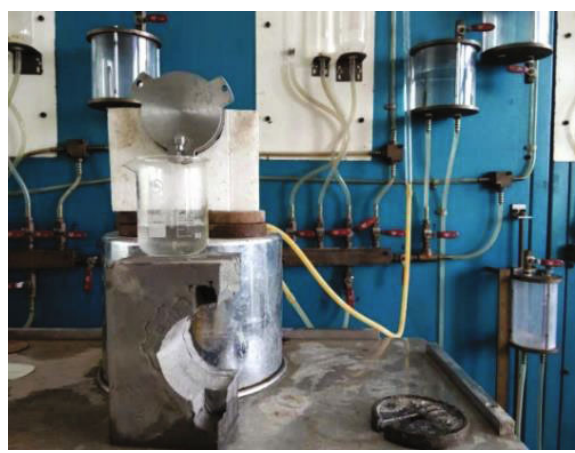

(a)

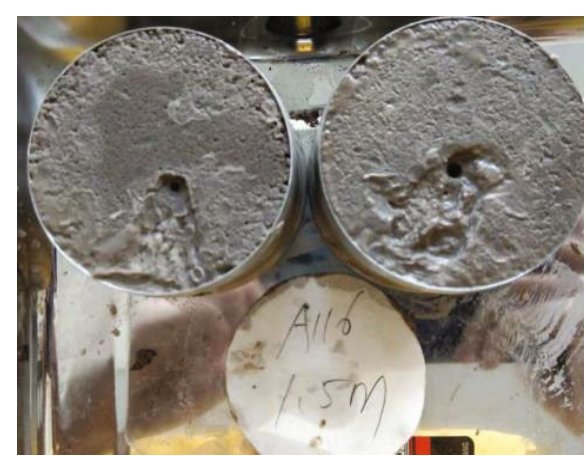

(b)

FIgURE 7: Pinhole experiment: (a) pinhole experimental device; (b) aperture observation of pinhole experiment.

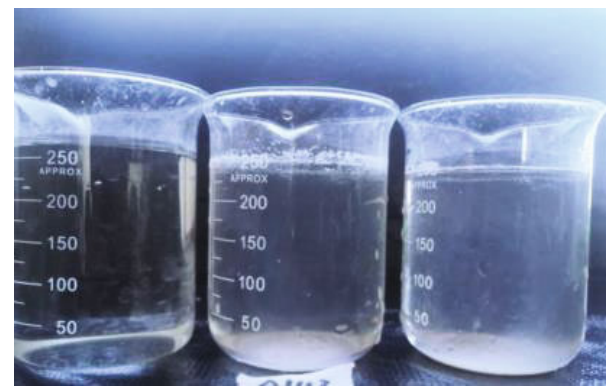

FIGURE 8: Fragment test.

TABLE 3: Empirical values of SAR.

\begin{tabular}{lc}
\hline TDS $(\mathrm{mEq} / \mathrm{L})$ & Approximate SAR for dispersive soil \\
\hline 5 & $>2.7$ \\
10 & $>4.2$ \\
100 & $>13.0$ \\
\hline
\end{tabular}

quantitatively determined by the ratio of the content of exchangeable $\mathrm{Na}^{+}$and the sum of exchangeable cations [18]. The judgment standards were as follows: ESP $<7$ : nondispersive soil; $7 \leq \mathrm{ESP}<10$ : transitional soil; ESP $\geq 10$ : dispersive soil. The calculation formula is as follows:

$$
\mathrm{ESP}=\frac{\overline{\mathrm{Na}}}{\mathrm{CEC}} \times 100,
$$

where $\overline{\mathrm{Na}}$ is the content of exchangeable $\mathrm{Na}^{+}$ions $(\mathrm{mEq} / \mathrm{L})$ after an elution with $50 \%$ alcohol followed by an elution with a $\mathrm{pH}=9$ ammonium acetate-ammonium hydroxide solution; $\overline{\mathrm{Na}}$ is determined by atomic absorption spectrometry. Moreover, CEC is the total amount of cation exchange $(\mathrm{mEq} / \mathrm{L})$, which is determined by the conventional ammonium acetate method.

3.6. Tests of the Improvement of Dispersive Soil. In the past, only lime was usually added to improve the dispersive soil at seasonally frozen regions in China. However, practice has shown that this method does not have an ideal effect, and there are problems in the corrosion and erosion resistance of dispersive soil treated by this method. Furthermore, its durability in freeze-thaw cycles in cold regions is substandard. According to the properties of soil in this study area, two improvement schemes of the addition of lime and fly ash (at a ratio of $1: 2$ ) and cement, lime, and fly ash (at a ratio of $1: 1: 4)$ are proposed to improve the dispersion of the soil. The effect of the improvement was evaluated by a pinhole test and a fragmentation test.

\section{Experimental Results and Discussion}

4.1. Analysis of the Test Results. To comprehensively appraise the dispersibility of the soil in the study area, based on various test methods, a comprehensive appraisal of the dispersibility was performed.

4.1.1. Double Hydrometer Method. Using a hydrometer, 89 sets of experiments were performed in total. Among them, only one sample had a dispersion degree below 30\%, which indicates nondispersive soil; the other samples had a dispersion degree of $30-50 \%$ and were determined to be transitional soil. Figure 9(a) reveals that the pseudopowder property of the soil particles was destroyed after the addition of a dispersant, and the content of clay particles was higher than that without added dispersant. As shown in Figure 9(a), when the content of clay particles increased, the dispersion value tended to increase. Furthermore, Figure 9(b) indicates that the dispersion of the soil samples was normally distributed. The degree of dispersion was mostly distributed between 75 and 95\%, and the degree of $85 \%$ accounted for more than $80 \%$ of the samples.

4.1.2. Pinhole Experiment. Among the soil samples obtained from the A1 soil material yard, 89 groups of soil samples were selected for the pinhole experiment, the results of which are reported in Table 4. Among them, 12 groups of samples had a postexperimental pore size that was 2-3 times larger than the original pore size, but the color of the water at the end of the experiment was transparent. Therefore, these samples were determined to be transitional soil (ND3). The postexperimental pore size of 38 groups of samples was 1.5-3 times larger than the original pore size, but the color of water became turbid. Therefore, these samples were determined to be dispersive soil (D2). The postexperimental pore size of 39 samples was 2.5-5 times larger than 


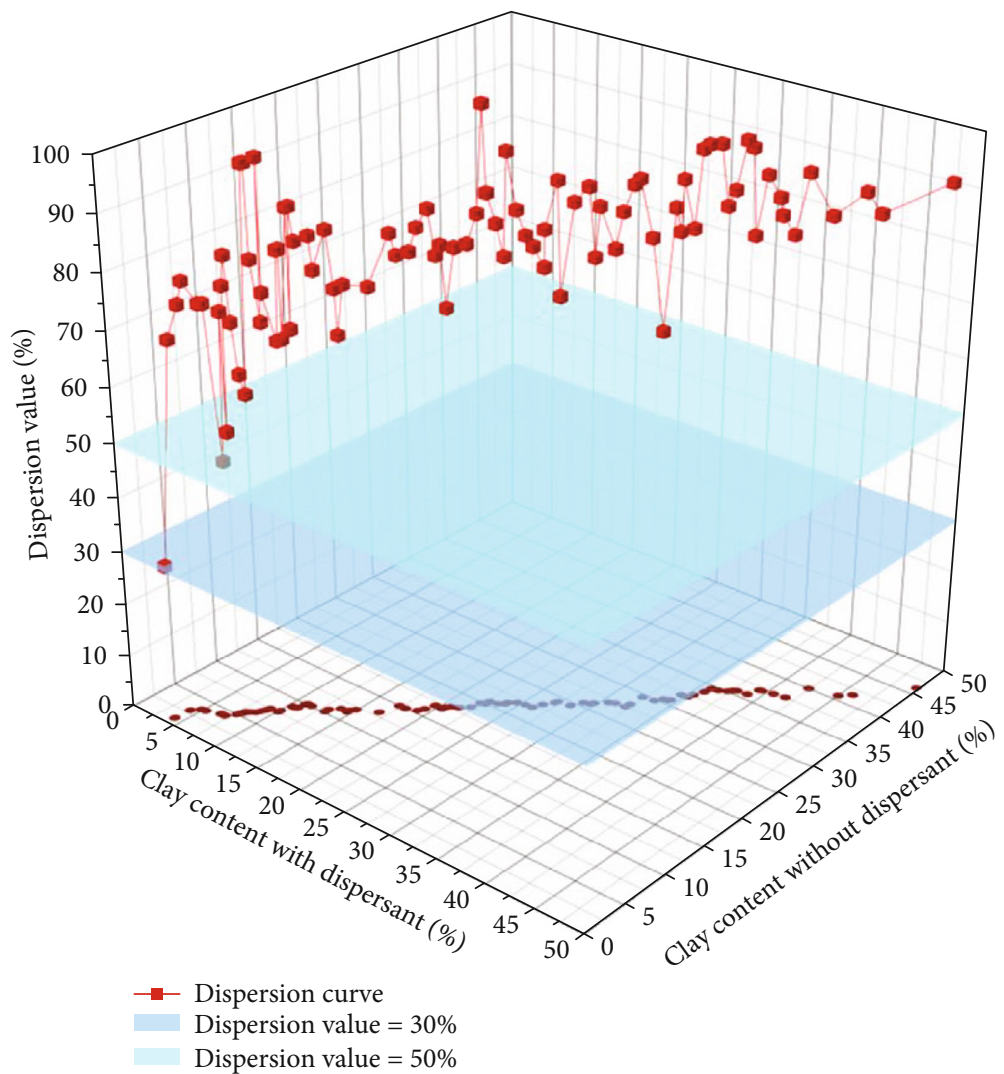

(a)

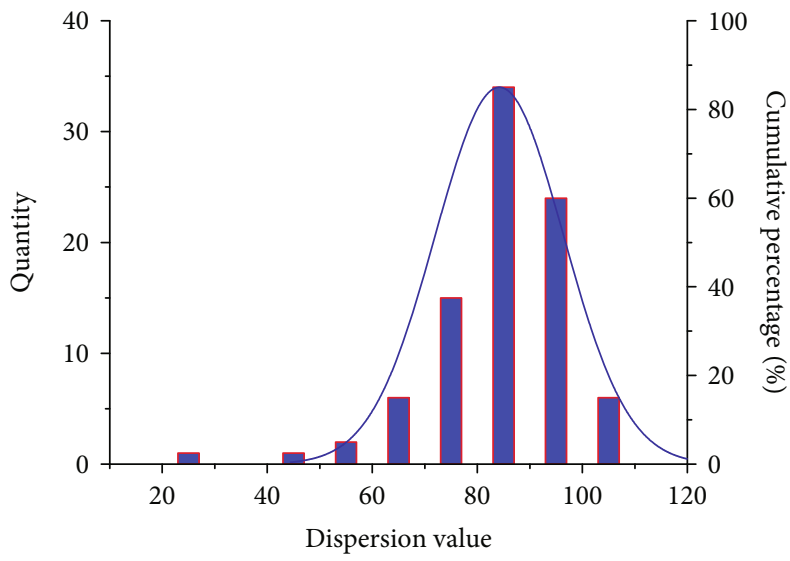

(b)

FIgURE 9: Results of the double hydrometer experiment: (a) comparison of the clay content under the two test conditions; (b) curve of the dispersion distribution.

the original pore size, and the water was turbid after the test; these samples were determined to be highly dispersive soil (D1). The results of the pinhole experiment reveal that most of the samples in the soil material yard were dispersive soil (Table 4).

4.1.3. Fragmentation Test. In total, 89 groups of 178 soil samples were tested for fragmentation, and the experimental results were analyzed according to the judgment criteria in Section 3.3. The results are exhibited in Figure 10. Nine samples were found to be Class I, accounting for $5 \%$ of the total;
48 samples were identified as Class II, accounting for $27 \%$ of the total; 4 samples were identified as Class III, accounting for $2 \%$ of the total; finally, 117 samples were identified as Class IV, accounting for $66 \%$ of the total. Based on the preceding analysis, $95 \%$ of the samples had a dispersive reaction during the fragmentation test.

4.1.4. Sodium Adsorption Ratio (SAR). The method in Section 3.4 was used to perform the SAR test for 24 groups of samples, and the SAR value of each soil sample was calculated by Equation (2). In combination with the TDS values 
TABLE 4: Results of the pinhole experiment.

\begin{tabular}{cccc}
\hline Quantity & $\begin{array}{c}\text { Multiples of aperture } \\
\text { (as compared to the } \\
\text { aperture before } \\
\text { experiment) }\end{array}$ & $\begin{array}{c}\text { Color of the } \\
\text { water at the end } \\
\text { of experiment }\end{array}$ & $\begin{array}{c}\text { Dispersibility } \\
\text { identification } \\
\text { result }\end{array}$ \\
\hline 12 & $2.0-3.0$ & Transparent & $\begin{array}{c}\text { ND3: } \\
\text { transitional } \\
\text { soil } \\
\text { D2: dispersive } \\
\text { soil } \\
\text { D1: highly } \\
\text { dispersive soil }\end{array}$ \\
\hline
\end{tabular}

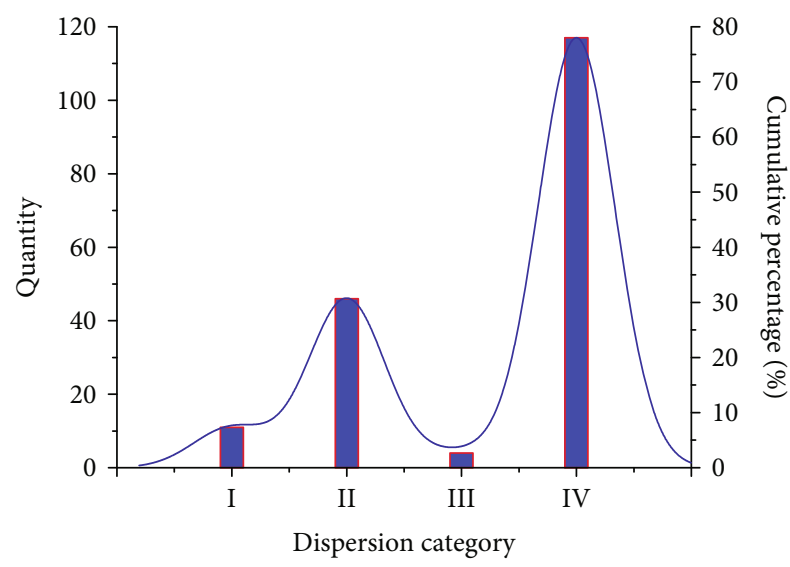

Figure 10: Statistical results of the fragmentation test.

and Table 3, the distribution range of soil dispersion is presented in Figure 11.

The dispersion of each sample was preliminarily determined, and the results demonstrated the presence of a small amount of transitional soil in addition to dispersive soil. However, previous studies have shown that the experimental results of some dispersive soil identified by pinhole tests may be distributed. To verify the dispersibility of such soil, the $K$ index is adopted for verification [19], as given by

$$
K=\frac{\mathrm{Na}^{+}+\mathrm{K}^{+}}{\sqrt{\mathrm{Ca}^{2+}+\mathrm{Mg}^{2+}}}
$$

In Equation (4), the unit of ions is mEq/L. $K>0.3$, dispersive soil; $K<0.2$, nondispersive soil.

After the correction of the $K$ values in Table 5, all samples can be evidently identified as dispersive soil.

4.1.5. ESP + EMgP Numerical Method. According to the ESP test results, some of the soil samples preliminarily determined as transitional soil exhibited dispersibility with other test methods, since only the influence of $\mathrm{Na}^{+}$was considered in Equation (3) (Section 3.5). In fact, because the content of cations in the soil affects its dispersibility, the soil dispersibility requires further investigation. Considering the high content of $\mathrm{Mg}^{2+}$ in the soil and the $\mathrm{pH}$ range of 8.43-8.91 of the soil samples in the study area, the environmental conditions for the formation of dispersive soil are in place. Thus, the $\mathrm{ESP}+\mathrm{EMgP}$ numerical method (proposed by the Bureau of Reclamation of the U.S. Department of Interior) was used to further determine the dispersion of the soil samples from the study area after the initial ESP determination, and the flow chart is presented in Figure 12. The value of EMgP can be calculated by

$$
\mathrm{EMgP}=\frac{\overline{\mathrm{Mg}}}{\mathrm{CEC}} \times 100 .
$$

The calculation results of the EMgP method are reported in Table 6. When only $\mathrm{Na}^{+}$was considered, the ESP calculation results demonstrated a transitional soil distribution in the study area. However, after considering the effect of the $\mathrm{Mg}^{2+}$ content, the ESP + EMgP numerical method results revealed that all samples were dispersive soil.

4.1.6. Comprehensive Discriminant Analysis. Five kinds of dispersion experiment were conducted in this study. Different experiment methods may produce different results for the same sample. It shows that all the existing experiment methods have the defects of semiexperience, which indicates that although the methods to discriminate dispersive soil have been mastered, the reliability of each method remains questionable. Thus, mineral analysis and the $\mathrm{pH}$ value should be combined to comprehensively determine based on the results of the five test methods. The results of the present research demonstrate that all soil samples from the study area were dispersive. Gullies and holes are commonly developed at the material yard and are typical characteristics of dispersive land. Based on these factors, it can be concluded that the soil of this yard material is characterized by dispersibility, and most of the soil is highly dispersive. Thus, the soil in this area should be improved to reduce or even eliminate its dispersibility to facilitate its use as a dam filling material.

4.2. Analysis of Improvement Experiment Results. To explore the effect of the use of $\mathrm{L}_{1} \mathrm{Fa}_{2}$ and $\mathrm{C}_{1} \mathrm{~L}_{1} \mathrm{Fa}_{4}$ to improve the soil samples, dispersion investigations of the dispersive and transitional soil after improvement were performed by a pinhole test and a fragmentation test. The experimental results are presented in Figure 13.

The results of the pinhole experiment reveal that both dispersive and transitional soils exhibited the characteristics of nondispersive soil after treatment with different dosages of $\mathrm{L}_{1} \mathrm{Fa}_{2}$ and $\mathrm{C}_{1} \mathrm{~L}_{1} \mathrm{Fa}_{4}$, respectively. When the contents of the two improvement measures were $4 \%$ and $6 \%$, dispersive soil had the lowest flow at the end of the test, which indicates that these contents had the best effect on the improvement of dispersive soil. When the contents of the two improvement measures were $5 \%$ and $3 \%$, transitional soil had the lowest flow at the end of the test, which indicates that these contents had the best effect on the improvement of transitional soil. In the fragmentation test, when the $\mathrm{L}_{1} \mathrm{Fa}_{2}$ content was $4 \%$, both dispersive and transitional soils fell into dispersive Class I. When the $\mathrm{C}_{1} \mathrm{~L}_{1} \mathrm{Fa}_{4}$ content was $6 \%$, the dispersibilities of both dispersive and transitional soil were 


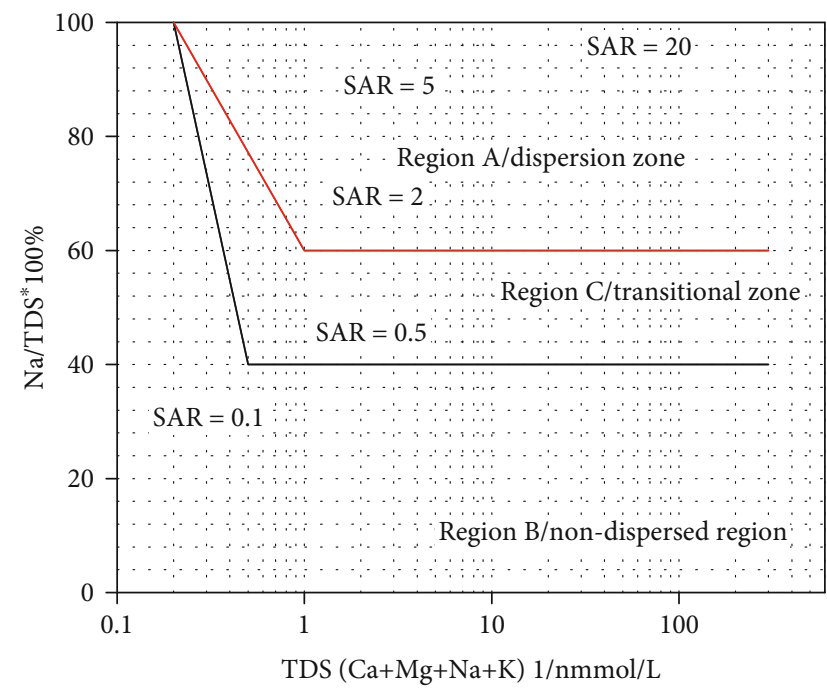

FIGURE 11: Relationships among the dispersion of soil and $M_{\mathrm{TDS}}, C_{\mathrm{PS}}$, and the soluble salt content $[5,32]$. The total amount of soluble salt in pore water is calculated as follows: $M_{\mathrm{TDS}}=M_{\mathrm{Ca}}+M_{\mathrm{Mg}}+M_{\mathrm{Na}}+M_{\mathrm{K}}$. The mole percentage of $\mathrm{Na}^{+}$is calculated as follows: $C_{\mathrm{PS}}=\left(M_{\mathrm{Na}} /\right.$ $\left.M_{\text {TDS }}\right) \times 100 \%$. The sum of the contents of the four cations $\mathrm{K}^{+}, \mathrm{Na}^{+}, \mathrm{Ca}^{2+}$, and $\mathrm{Mg}^{2+}$ is the TDS, which is measured in milligram equivalents per liter $(\mathrm{mEq} / \mathrm{L})$.

TABLE 5: Experimental results of SAR.

\begin{tabular}{|c|c|c|c|c|c|c|c|c|}
\hline \multirow[t]{2}{*}{ Soil sample } & \multicolumn{3}{|c|}{$\begin{array}{l}\text { Contents of cations in pore water } \\
\qquad(\mathrm{mEq} / \mathrm{L})\end{array}$} & \multirow[t]{2}{*}{$\mathrm{Na}^{+}(\%)$} & \multirow[t]{2}{*}{ TDS (mEq/L) } & \multirow[t]{2}{*}{ SAR } & \multirow[t]{2}{*}{ K } & \multirow[t]{2}{*}{ Dispersibility identification } \\
\hline & $\mathrm{Na}^{+}$ & $\mathrm{K}^{+}$ & $\mathrm{Ca}^{2+}+\mathrm{Mg}^{2+}$ & & & & & \\
\hline $1-01$ & 65.83 & 0.11 & 9.14 & 87.68 & 75.08 & 30.80 & 21.81 & \multirow{24}{*}{ Dispersive soil } \\
\hline $1-02$ & 77.05 & 0.43 & 24.67 & 75.43 & 102.15 & 21.94 & 15.60 & \\
\hline $1-03$ & 97.64 & 0.14 & 8.68 & 91.71 & 106.46 & 46.87 & 33.19 & \\
\hline $1-04$ & 75.89 & 0.11 & 6.62 & 91.85 & 82.63 & 41.70 & 29.53 & \\
\hline $1-05$ & 247.22 & 0.42 & 48.43 & 83.50 & 296.07 & 50.24 & 35.58 & \\
\hline $1-06$ & 60.14 & 0.11 & 7.77 & 88.42 & 68.01 & 30.52 & 21.62 & \\
\hline $1-07$ & 169.81 & 0.30 & 8.22 & 95.22 & 178.33 & 83.74 & 59.32 & \\
\hline $1-08$ & 23.25 & 3.46 & 13.25 & 58.19 & 39.96 & 9.03 & 7.34 & \\
\hline $1-09$ & 14.66 & 0.26 & 24.21 & 37.46 & 39.13 & 4.21 & 3.03 & \\
\hline $1-10$ & 88.94 & 2.20 & 56.65 & 60.18 & 147.79 & 16.71 & 12.11 & \\
\hline $1-11$ & 39.56 & 1.59 & 19.65 & 65.07 & 60.79 & 12.62 & 9.28 & \\
\hline $1-12$ & 97.22 & 0.20 & 10.97 & 89.70 & 108.38 & 41.52 & 29.42 & \\
\hline $1-13$ & 79.76 & 0.88 & 63.96 & 55.16 & 144.60 & 14.10 & 10.08 & \\
\hline $1-14$ & 45.91 & 0.28 & 14.62 & 75.49 & 60.81 & 16.98 & 12.08 & \\
\hline $1-15$ & 103.61 & 0.15 & 22.16 & 82.28 & 125.92 & 31.13 & 22.04 & \\
\hline $1-16$ & 90.98 & 2.32 & 53.46 & 61.99 & 146.76 & 17.60 & 12.76 & \\
\hline $1-17$ & 220.28 & 0.29 & 12.34 & 94.58 & 232.90 & 88.70 & 62.80 & \\
\hline $1-18$ & 27.85 & 0.26 & 9.37 & 74.32 & 37.47 & 12.87 & 9.18 & \\
\hline $1-19$ & 36.96 & 0.16 & 8.00 & 81.93 & 45.11 & 18.48 & 13.13 & \\
\hline $1-20$ & 42.53 & 0.14 & 9.37 & 81.73 & 52.04 & 19.65 & 13.94 & \\
\hline $1-21$ & 41.03 & 0.17 & 14.16 & 74.11 & 55.37 & 15.42 & 10.95 & \\
\hline $1-22$ & 42.53 & 1.73 & 15.53 & 71.13 & 59.80 & 15.26 & 11.23 & \\
\hline $1-23$ & 147.17 & 2.20 & 31.07 & 81.57 & 180.43 & 37.34 & 26.80 & \\
\hline $1-24$ & 159.42 & 0.34 & 12.11 & 92.76 & 171.86 & 64.79 & 45.91 & \\
\hline
\end{tabular}




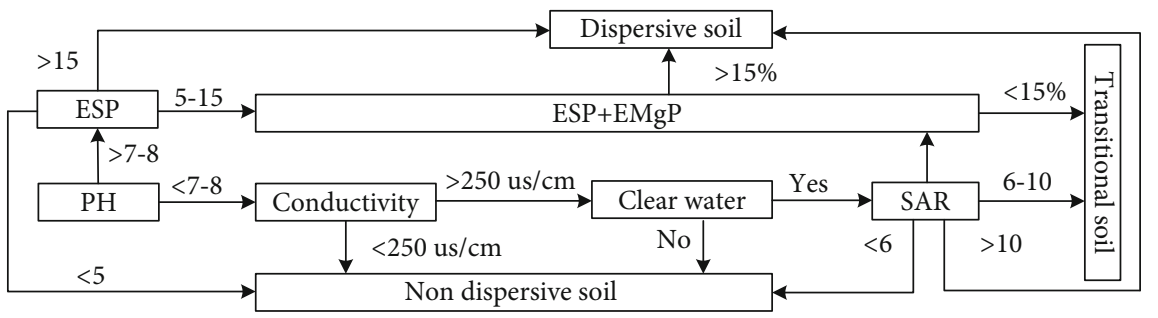

FIGURE 12: Flow chart of the ESP + EMgP numerical method.

TABle 6: Determination results of the ESP + EMgP numerical method (ND: transitional soil; D: dispersive soil).

\begin{tabular}{|c|c|c|c|c|c|c|}
\hline Soil sample & $\mathrm{Na}^{+}$ & $\begin{array}{r}\text { Cation exchange capacity CEC } \\
\mathrm{mEq} / 100 \mathrm{~g} \text { soil }\end{array}$ & $\mathrm{ESP}=\mathrm{Na} * 100 / \mathrm{CEC}$ & Preliminary determination & $\mathrm{ESP}+\mathrm{EMgP}$ & Final determination \\
\hline $2-01$ & 2.43 & 10.6 & 22.93 & ND & 23.29 & $\mathrm{D}$ \\
\hline $2-02$ & 0.64 & 8.62 & 7.38 & ND & 15.89 & $\mathrm{D}$ \\
\hline $2-03$ & 4.26 & 10.54 & 40.37 & $\mathrm{D}$ & 40.94 & $\mathrm{D}$ \\
\hline $2-04$ & 5.34 & 14.68 & 36.39 & $\mathrm{D}$ & 36.59 & $\mathrm{D}$ \\
\hline $2-05$ & 9.59 & 8.08 & 118.73 & $\mathrm{D}$ & 124.28 & $\mathrm{D}$ \\
\hline $2-06$ & 2.69 & 12.07 & 22.28 & $\mathrm{D}$ & 23.15 & $\mathrm{D}$ \\
\hline $2-07$ & 15.25 & 11.29 & 135.12 & $\mathrm{D}$ & 135.25 & $\mathrm{D}$ \\
\hline $2-08$ & 0.48 & 5.83 & 8.27 & ND & 16.93 & $\mathrm{D}$ \\
\hline $2-09$ & 0.29 & 3.9 & 7.47 & ND & 16.65 & $\mathrm{D}$ \\
\hline $2-10$ & 0.74 & 6.84 & 10.82 & $\mathrm{D}$ & 19.34 & $\mathrm{D}$ \\
\hline $2-11$ & 0.83 & 1.52 & 54.77 & $\mathrm{D}$ & 68.53 & $\mathrm{D}$ \\
\hline $2-12$ & 2.21 & 4.78 & 46.31 & $\mathrm{D}$ & 48.35 & $\mathrm{D}$ \\
\hline $2-13$ & 2.24 & 5.55 & 40.39 & $\mathrm{D}$ & 47.39 & $\mathrm{D}$ \\
\hline $2-14$ & 0.43 & 5.87 & 7.36 & ND & 15.69 & $\mathrm{D}$ \\
\hline $2-15$ & 0.81 & 6.2 & 13.14 & $\mathrm{D}$ & 16.4 & $\mathrm{D}$ \\
\hline $2-16$ & 6.66 & 5.2 & 128.13 & $\mathrm{D}$ & 135.6 & $\mathrm{D}$ \\
\hline $2-17$ & 2.24 & 5.37 & 41.73 & $\mathrm{D}$ & 43.68 & $\mathrm{D}$ \\
\hline $2-18$ & 0.41 & 4.97 & 8.19 & ND & 16.18 & $\mathrm{D}$ \\
\hline $2-19$ & 2.55 & 8.29 & 30.69 & $\mathrm{D}$ & 31.41 & $\mathrm{D}$ \\
\hline $2-20$ & 2.61 & 15.02 & 17.36 & $\mathrm{D}$ & 17.91 & $\mathrm{D}$ \\
\hline $2-21$ & 0.38 & 5.01 & 7.63 & ND & 15.86 & $\mathrm{D}$ \\
\hline $2-22$ & 3.21 & 6.9 & 46.52 & $\mathrm{D}$ & 49.12 & $\mathrm{D}$ \\
\hline $2-23$ & 10.49 & 8.09 & 129.72 & $\mathrm{D}$ & 132.31 & $\mathrm{D}$ \\
\hline $2-24$ & 13.33 & 4.82 & 276.38 & $\mathrm{D}$ & 278.39 & $\mathrm{D}$ \\
\hline
\end{tabular}

between Classes I and II, and the dispersibility was low. Based on the test results, $4 \%$ lime and fly ash at a ratio of $1: 2$ should be added to improve the dispersive and transitional soil in this area.

\section{Conclusions}

In this research, to study the dispersibility of the soil in the study area of Hua'ao Lake, Qian'an County, Jilin Province, China, the value distribution of $\mathrm{pH}$ in the study area was investigated, and three physical experiments (a double hydrometer test, a pinhole test, and a debris test) and two chemical experiments (a sodium adsorption ratio test and the ESP + EMgP numerical method) of dispersive soil were performed. The results of the pinhole test and fragmentation test depend on empirical judgment and can only be used to qualitatively determine the dispersion of the graph. Although the double hydrometer test can quantitatively determine the dispersion of soil, it can only consider the influence of the clay content of soil, and the considered factors are not sufficiently comprehensive. The exchangeable sodium ion test and ESP + EMgP numerical method can be used to quantitatively determine the dispersion of soil according to the content of cations in the soil. Moreover, they can be used to correct the inaccuracies of physical experiments, and the results are highly credible. According to the experimental results and combined with the typical appearance of dispersive soil in the study area, the comprehensive judgment results reveal that the soil in the study area has dispersibility, and most of the dispersibility is high. 

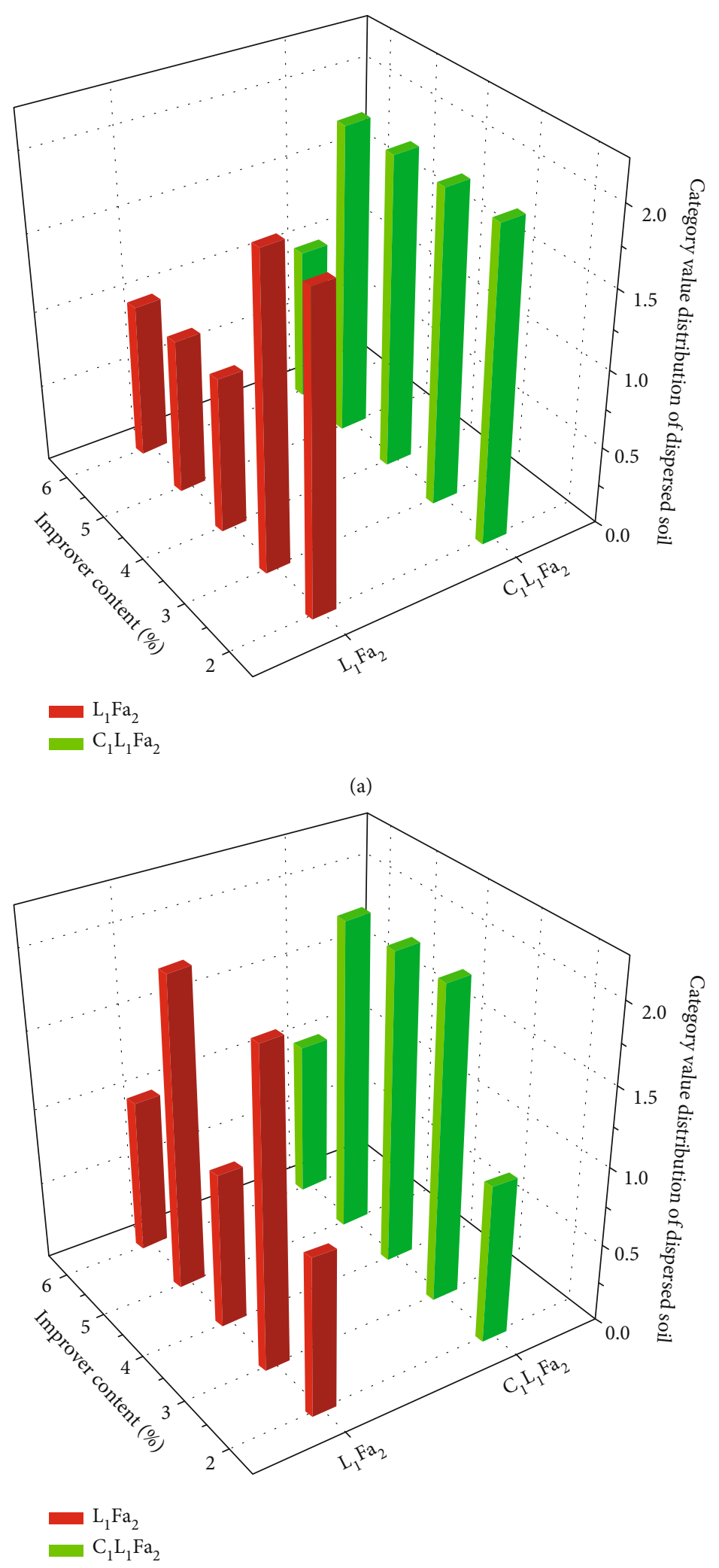

(b)

Figure 13: Continued. 


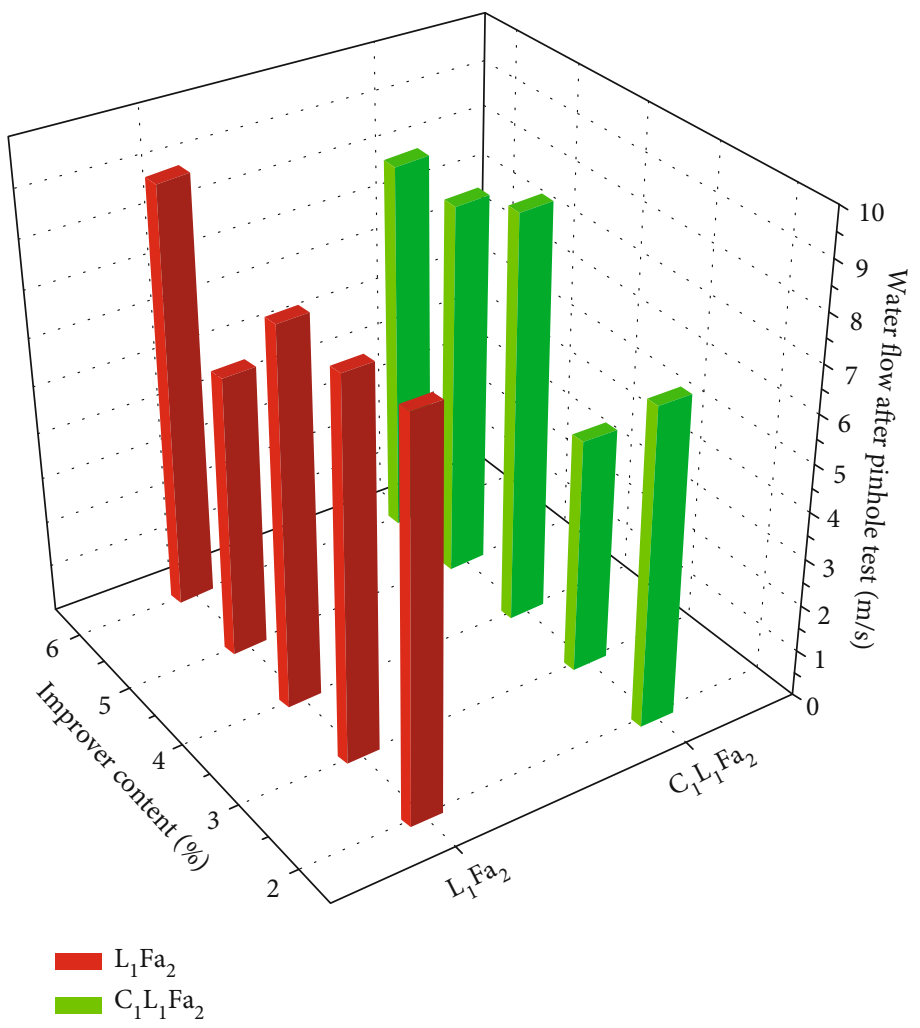

(c)

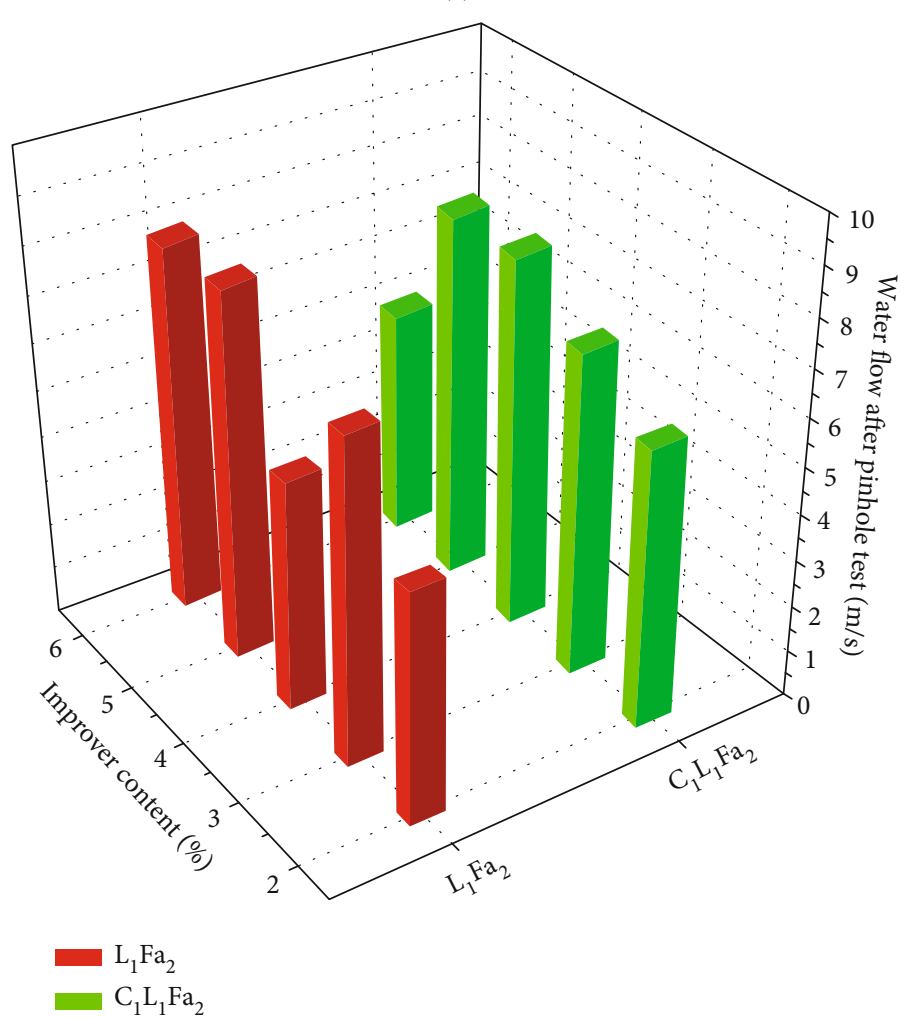

(d)

FIGURE 13: Results of the addition of two types of improvement measures $\left(\mathrm{L}_{1} \mathrm{Fa}_{2}\right.$ and $\left.\mathrm{C}_{1} \mathrm{~L}_{1} \mathrm{Fa}_{4}\right)$ to dispersive soil: (a) fragment test of the improved transitional soil; (b) fragmentation test of the improved dispersive soil; (c) pinhole test of the improved transitional soil; (d) pinhole test of the improved dispersive soil. 
Thus, for use as a dam filling material, the soil in the study area must be improved to eliminate its dispersion.

The results of the fragmentation test and pinhole test after the improvement of dispersive soil reveal that both $\mathrm{L}_{1} \mathrm{Fa}_{2}$ and $\mathrm{C}_{1} \mathrm{~L}_{1} \mathrm{Fa}_{4}$ can improve the dispersibility of soil in the study area. Based on comprehensive judgment, a $4 \%$ addition of $\mathrm{L}_{1} \mathrm{Fa}_{2}$ has the best improvement effect on the dispersive soil in this area.

\section{Data Availability}

The data used to support the findings of this study are included within the article. The data are available from the corresponding author upon request. The e-mail is ruifu13@163.com.

\section{Conflicts of Interest}

The authors declare that they have no conflicts of interest.

\section{Acknowledgments}

This study was supported by Jilin Province Water Resource and Hydropower Consultative Company of China and the supported subject was "Water Environment Treatment Project, Qian'an County, Jilin Province.”

\section{References}

[1] J. Zhang, Q. Wang, W. Wang, and X. Zhang, "The dispersion mechanism of dispersive seasonally frozen soil in western Jilin Province," Bulletin of Engineering Geology and the Environment, vol. 80, no. 7, pp. 5493-5503, 2021.

[2] W. Huang, "Experimental study on the dispersion of soil material in a reservoir in Qingyang, China," Water Sciences and Engineering Technology, vol. 5, pp. 70-73, 2020.

[3] J. L. Sherard, R. S. Decker, and N. L. Ryker, "Piping in the earth dams of dispersive clay," in Proceedings of the Special Conference on Performance of Earth and Earth-supported Structures, vol. 1, pp. 589-626, Purdue University, Indiana, 1972.

[4] M. J. Deng, X. B. Zhou, and J. P. Wan, "Experimental study on dispersion of impermeable soil material for dam core wall of “635” hydropower project," Journal of Geotechnical Engineering, vol. 6, pp. 673-677, 2000.

[5] F. Gutiérrez, G. Desir, and M. Gutiérrez, "Causes of the catastrophic failure of an earth dam built on gypsiferous alluvium and dispersive clays (Altorricón, Huesca Province, NE Spain)," Environmental Geology, vol. 43, no. 7, pp. 842-851, 2003.

[6] L. Wang, X. Yuan, and M. Wang, "Landslide failure mechanisms of dispersive soil slopes in seasonally frozen regions," Advances in Civil Engineering, vol. 2020, no. 9, 2020.

[7] F. U. Ismail, Z. Mohamed, and M. Mukri, "A study on the mechanism of internal erosion resistance to soil slope instability," Electronic Journal of Geotechnical Engineering, vol. 13, 2008.

[8] K. L. Tian, H. L. Zhang, and H. H. Fan, "A review on the identification methods and engineering control measures of dispersed clay," Journal of Hydropower Engineering, vol. 29, no. 2, pp. 204-209, 2010.
[9] ASTM, Standard Test Method for Dispersive Characteristics of Clay Soil by Double Hydrometer (D4221-18), West Conshohocken.PA: ASTM International, 2011.

[10] ASTM, Standard Test Methods for Determining Dispersive Characteristics of Clayey Soils by the Crumb Test (D6572-06), West Conshohocken.PA: ASTM International, 2006.

[11] ASTM, Standard Test Method for Identification and Classification of Dispersive Clay Soils by the Pin-Hole Test (D4647-13), West Conshohocken.PA: ASTM International, 2009.

[12] Z. Y. Shi, "Study on comprehensive discrimination method of soil dispersity," Chinese Journal of Engineering Geology, vol. 28, no. 3, pp. 482-489, 2020.

[13] W. M. Peng, "Experimental study on the dispersion of a low liquid limit clay," Chinese Journal of Geotechnical Engineering, vol. 42, pp. 121-126, 2020.

[14] Y. C. Zhu, A. Marchuk, and M. L. Bennett, "Ionicity of claycation bonds in relation to dispersive behavior of $\mathrm{Mg}$ and $\mathrm{K}$ soil clays as influenced by $\mathrm{pH}$," Clays and Clay Minerals, vol. 68 , no. 6 , pp. 588-600, 2020.

[15] O. G. Ingles and G. D. Aitchison, Soil-Water Disequilibrium as a Cause of Subsidence in Natural Soils and Earth Embankments, International Syp, on Land Subsidence (Tokyo), 1970.

[16] X. Zhang, E. Zhai, Y. Wu, D. Sun, and Y. Lu, "Theoretical and numerical analyses on hydro-thermal-salt-mechanical interaction of unsaturated salinized soil subjected to typical unidirectional freezing process," International Journal of Geomechanics, vol. 21, no. 7, 2021.

[17] F. Liu, B. Wang, M. Wang, and X. Yuan, "Analysis on pore structure of non-dispersible underwater concrete in saline soil area," Journal of Renewable Materials, vol. 9, no. 4, pp. 723742, 2021.

[18] H. Abbaslou, H. Hadifard, and A. R. Ghanizadeh, "Effect of cations and anions on flocculation of dispersive clayey soils," Heliyon, vol. 6, no. 2, p. e03462, 2020.

[19] X. C. Zhang and L. D. Norton, "Effect of exchangeable Mg on saturated hydraulic conductivity, disaggregation and clay dispersion of disturbed soils," Journal of hydrology (Amsterdam), vol. 260, no. 1-4, pp. 194-205, 2002.

[20] X. D. Zhang, "Dispersion of soil in a dry "mud forest"," Journal of Northeastern University (Natural Science), vol. 36, no. 11, pp. 1643-1647, 2015.

[21] X. Zhang, Y. Wu, E. Zhai, and P. Ye, "Coupling analysis of the heat-water dynamics and frozen depth in a seasonally frozen zone," Journal of Hydrology, vol. 593, p. 125603, 2021.

[22] C. Li, "Microbial mineralization based on urease induced calcium carbonate precipitation technology in the application of experimental study on the dispersion of soil improvement," Geotechnical, vol. 42, no. 2, pp. 333-342, 2021.

[23] H. Savaş, M. Türköz, E. Seyrek, and E. Ünver, "Comparison of the effect of using class $\mathrm{C}$ and $\mathrm{F}$ fly ash on the stabilization of dispersive soils," Arabian Journal of Geosciences, vol. 11, no. 20, 2018.

[24] H. Savas, "Consolidation and swell characteristics of dispersive soils stabilized with lime and natural zeolite," Science and Engineering of Composite Materials, vol. 23, no. 6, pp. 589-598, 2016.

[25] H. C. S. F. Consoli, "Sustainable binders stabilizing dispersive clay," Journal of Materials in Civil Engineering, vol. 33, no. 3, 2021. 
[26] J. R. Joga and B. J. S. Varaprasad, "Effect of xanthan gum biopolymer on dispersive properties of soils," World Journal of Engineering, vol. 17, no. 4, pp. 563-571, 2020.

[27] M. Hassanlourad, "Dispersive clay stabilised by alum and lime," International Journal of GEOMATE, vol. 12, no. 29, pp. 156-162, 2017.

[28] B. G. Gidday and S. Mittal, "Improving the characteristics of dispersive subgrade soils using lime," Heliyon, vol. 6, no. 2, p. e03384, 2020.

[29] A. R. Goodarzi and M. Salimi, "Stabilization treatment of a dispersive clayey soil using granulated blast furnace slag and basic oxygen furnace slag," Applied Clay Science, vol. 108, pp. 61-69, 2015.

[30] S. Mohanty, N. Roy, S. P. Singh, and P. Sihag, "Estimating the strength of stabilized dispersive soil with cement clinker and fly ash," Geotechnical and Geological Engineering, vol. 37, no. 4, pp. 2915-2926, 2019.

[31] P. Sihag, M. Suthar, and S. Mohanty, "Estimation of UCS-FT of dispersive soil stabilized with fly ash, cement clinker and GGBS by artificial intelligence," Iranian Journal of Science and Technology, Transactions of Civil Engineering, vol. 45, no. 2, pp. 901-912, 2021.

[32] A. H. Vakili, M. Kaedi, M. Mokhberi, M. R. B. Selamat, and M. Salimi, "Treatment of highly dispersive clay by lignosulfonate addition and electroosmosis application," Applied Clay Science, vol. 152, no. 4, pp. 1-8, 2018. 